RESEARCH ARTICLE

\title{
Socio economic and health challenges of internally-displaced persons as a result of 2012 flooding in Nigeria
}

\author{
O.S. Amoo ${ }^{1}$, S.I. Smith", ${ }^{1,}$, I.A.O. Ujah ${ }^{1}$, D. Oladele ${ }^{1}$, N. David ${ }^{1}$, K.S. Oyedeji ${ }^{1}$, F. Nwaokorie ${ }^{1}$, T.A. Bamidele ${ }^{1}$, E.E. \\ Afocha $^{1}$, O. Awoderu ${ }^{1}$, Y. Adesanmi ${ }^{1}$, J. Iwuora ${ }^{1}$, A. Adeneye ${ }^{1}$, M. Bamidele ${ }^{1}$, S. Nduaga ${ }^{1}$, F. Ige ${ }^{1}$, B. Ajayi ${ }^{1}$, A.Z. \\ Musa $^{1}$, N. Idika ${ }^{1}$, O.C. Ezechi ${ }^{2}$ and A. Ajayi ${ }^{3}$ \\ ${ }^{1}$ Emergency Preparedness and Response Research Group, Nigerian Institute of Medical Research, Yaba, Lagos, Nigeria \\ ${ }^{2}$ Maternal and Child Health Reproductive Group, Nigerian Institute of Medical Research, Yaba, Lagos, Nigeria \\ ${ }^{3}$ Department of Microbiology, University of Lagos, Akoka, Nigeria
}

Received:29/11/2017; Accepted:15/05/2018

\begin{abstract}
Displaced people are faced with over-crowded conditions in camps with children being the most vulnerable. This is because they are faced with myriad of challenges such as poor nutrition, breakdown of health infrastructure, disease epidemics, looting and violence. Others include unprotected sex especially when separated from their families. Displaced persons are prey to a host of diseases, most of which could be prevented. In this study the socio-economic and health impacts among internally displaced persons (IDPs) following floods in Nigeria were identified. Information on social, economic and health issues obtained from 432 household heads, nursing mothers and pregnant women from 17 IDP camps in three states was analyzed using SPSS version 20.0. Majority (58\%) of IDPs had their occupation as farming and as a result of the flood, 299 (69.2\%) people lost their means of livelihood with a concomitant decrease in income to a mean of $\$ 35.2$. Victims' nutrition was affected, resulting $63.3 \%$ having less to eat. Though the major source of water to the IDPs before the flood was rivers/streams and wells, there was no statistical significance $(p=0.99)$ between the major source of water to the community even when they had access to pipe-borne water after the disaster.
\end{abstract}

Keywords: Internally Displaced Persons (IDPs), Socio-economic challenge, Flooding, Disaster.

\section{INTRODUCTION}

Floods are the most common natural disaster and have led to extensive morbidity and mortality throughout the world (Du et al., 2010). Loss of human life, damage to property, destruction of crops, loss of livestock, non-functioning infrastructure and deterioration of health condition owing to water-borne diseases are some of the immediate impacts of flooding (Mcmichael et al., 2003). In monetary terms, the extent of damages caused by floods is found to be dependent on the extent, depth and duration of flooding, and the velocities of flows in the flooded areas (The Associated Programme on Flood Management, 2006). Furthermore, it is dependent on the vulnerabilities of economic activities and communities (Armah et al., 2010; Lundgren and
Jonsson, 2012). Also, because communication links are disrupted and other infrastructure such as power plants, roads and bridges are damaged, economic activities come to a standstill, resulting in dislocation and dysfunction of normal life for a period much beyond the duration of the flooding. Similarly, the direct effect on production assets; be it in agriculture or industry, can inhibit regular activity and lead to loss of livelihoods, the spillover effects of which can be felt in business and commercial activities even in adjacent non-flooded areas. Since Nigeria's return to civil rule in 1999, thousands of people have been killed in recurring inter-communal conflicts and politically motivated violence that have also led to consistently large waves of internal displacement (Internal Displacement Monitoring Center, 2012). Flooding and forced evictions have caused further, significant population movements.

Nigeria is very prone to flooding mainly along the Niger River through Benue basin and Sokoto basin and this affects agricultural land use to a great extent. Many of the country's larger rivers have flood plains, which are subject to flooding during the rainy season. These include the Rivers Niger, Benue, Katsina and Imo. Urban flooding occurs in towns located on flat or low lying terrain (coastal areas) especially where little or no provision has been made for surface drainage, or where existing drainage has been blocked with municipal waste, refuse and eroded soil sediments (Oyinloye et al., 2013; WHO, 2013). Nigerian towns are generally characterized by poor drainage and are therefore subject to frequent flooding (Internal Displacement Monitoring Center, 2012).

Lagos, Ibadan, Aba, Calabar, Maiduguri, Port-Harcourt are major cities that are particularly affected by floods. An estimated 25 million people or $18 \%$ of Nigeria's population live in the coastal zone and are at risk of flooding (Babanyara et al., 2010). The areas that receive severe flooding impacts include the coastal areas of Lagos, Ondo, Delta, Bayelsa, Rivers, Akwa Ibom and Cross River states. Around a million people living on the low-lying terrains of the Niger 
River are considered at risk (Ologunorisa et al., 2010; Musa and Mynett, 2014). According to Nigeria Emergency Management Agency (NEMA), floods displaced thousands of people in 2011 and at least 500,000 in 2010 (Internal Displacement Monitoring Center, 2012).

The devastating effect of flooding has led to associated serious health problems and socio-economic implications. Displaced people are faced with being over-crowded in camps with their attendant adverse consequences. Some of such consequences include displaced children facing many dangers, especially if they have become separated from their families. The huge psycho-social effects on flood victims and their families can traumatize them for long periods of time (The Associated Programme on Flood Management, 2006; Awopetu et al., 2013). Loss of loved ones can generate deep impacts, especially on children. Displacement from one's home, loss of property, loss of objects valued for their connection with historical events, culture, or entertainment (memorabilia) and livelihoods, decreased levels of security in the aftermath of floods and in temporary shelters, and disruption to business and social affairs can cause stress (The Associated Programme on Flood Management, 2006; Awopetu et al., 2013). The stress of overcoming these losses can be overwhelming and produce lasting psychological impacts. Displaced children also miss out on education. Malnutrition levels are often high among displaced children and healthcare is either limited or lacking altogether (WHO, 2013). Poor nutrition, poor sanitary conditions, lack of potable water and lack of access to health services make IDPs prey to a host of diseases, most of which could be preventable. Such common disease conditions include diarrhoea, acute respiratory infections, tuberculosis, malaria, cholera, measles and meningitis. Other morbidity associated with floods is usually due to injuries, chemical hazards and mental health effects (WHO, 2013). The most common health-relevant occurrences during floods reported are shortages of safe water, injuries and disruption of access to health services. This study therefore aimed to identify the socio-economic, health challenges and the impacts of devastating flood among IDPs in Nigeria.

\section{MATERIALS AND METHODS}

In a cross sectional study between October and November 2012, quantitative household questionnaires were administered to 432 household heads, nursing mothers and pregnant women (randomly selected) from seventeen IDP camps in three of the states affected by severe flooding in Nigeria in 2012 namely Edo, Kogi and Benue States (Table 1). Benue, Edo and Kogi States were selected as the study sites because these states were located along the water basins and were the most affected states during the 2012 heavy rainfall in Nigeria. Primary data was obtained by administering questionnaire at household level so as to get very reliable and accurate information. The households were interviewed at the temporary camps for displaced persons. Information was obtained on means of livelihood, flood impact on health, infrastructures, education, source of water, coping strategy, housing and properties. Data obtained were analyzed using SPSS version 20.0.

\section{RESULTS}

Results showed that 237 (54.9\%) of respondents were male and 195 (45.1\%) were female which comprised of household heads, nursing mothers and pregnant women from the three states. The geographical distribution of respondents from the three states was Edo 164 (38\%), Benue 120 (27.8\%) and Kogi 148 (34.3\%). The age of the household heads ranged from 18 years to 100 years with majority (33\%) being in the 21-30 year age group (Figure 1) $81.2 \%$ of respondents were married while $7.9 \%$ were widowed. The majority of the respondents were farmers (58\%), followed by traders $(16.9 \%)$, Civil servants $(8.8 \%)$, students $(6.7 \%)$, unemployed $(3.7 \%)$, house wives $(2.3 \%)$ and least of all, professionals (1.4\%).

The income of respondents reduced from \$ 75.4-\$150.7 before the flooding to a mean of $\$ 35.2$ after the disaster. (Figure 2). A comparative analysis on the shelter types of IDPs show that majority were housed in schools (54\%), followed by Camps (30\%). Others include homes (8\%), relative's houses $(5 \%)$, home of friends $(2 \%)$ and the central library $(1 \%)$. Statistical analysis was significant in income rate before and after disaster $(\mathrm{p}=0.02)$. Furthermore, 299

Table 1: List of IDP Camps Visited in Three (3) States Affected By Flood in Nigeria.

\begin{tabular}{|c|c|c|c|}
\hline States & LGA & IDP Camp & No. of respondents \\
\hline \multirow{4}{*}{ EDO } & \multirow{2}{*}{ Etsako Central LGA } & Obe Primary School (OPS), Fugar & \multirow{4}{*}{164} \\
\hline & & Ekperi Grammar School (EGS), Fugar & \\
\hline & \multirow{2}{*}{ Etsako East LGA } & Omoaze Primary School, Aghenebode & \\
\hline & & Skills Acquisition Centre (SAC), Aghenebode & \\
\hline \multirow{4}{*}{ Kogi } & Lokoja LGA & St Luke’s Primary School (Adankolo) & \multirow{4}{*}{148} \\
\hline & Ajaokuta LGA & Model Primary School, Gadumo & \\
\hline & \multirow{2}{*}{ Idah LGA } & UEC Primary School , Idah & \\
\hline & & Pilot Primary School, Idah & \\
\hline \multirow{2}{*}{ Benue } & Makurdi LGA & St Catherine Primary school camp in Makurdi & \multirow{2}{*}{120} \\
\hline & Agatu LGA & LGA primary school, & \\
\hline
\end{tabular}




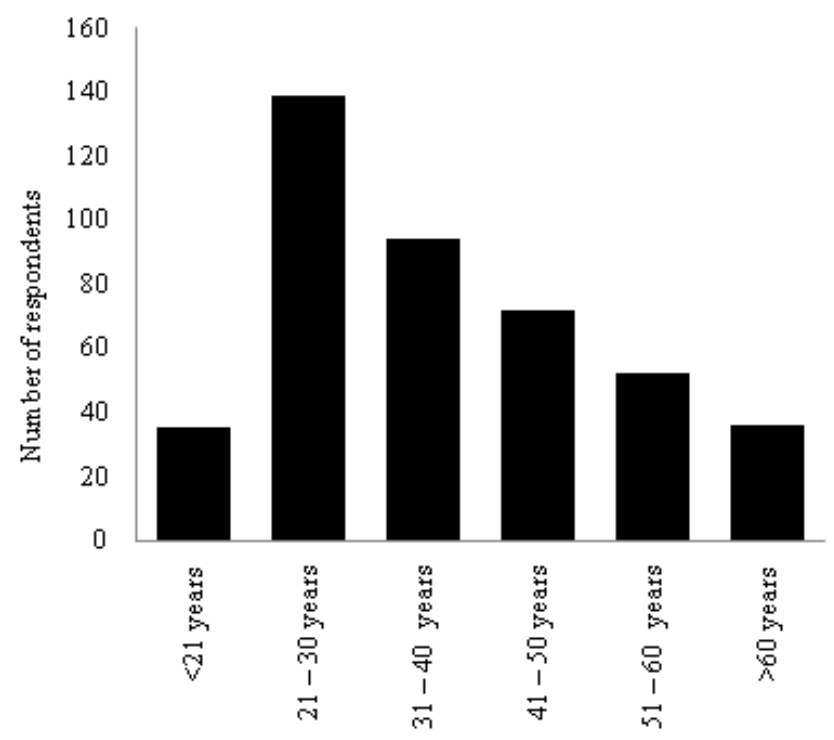

Figure 1: Distribution of the age groups of household heads.

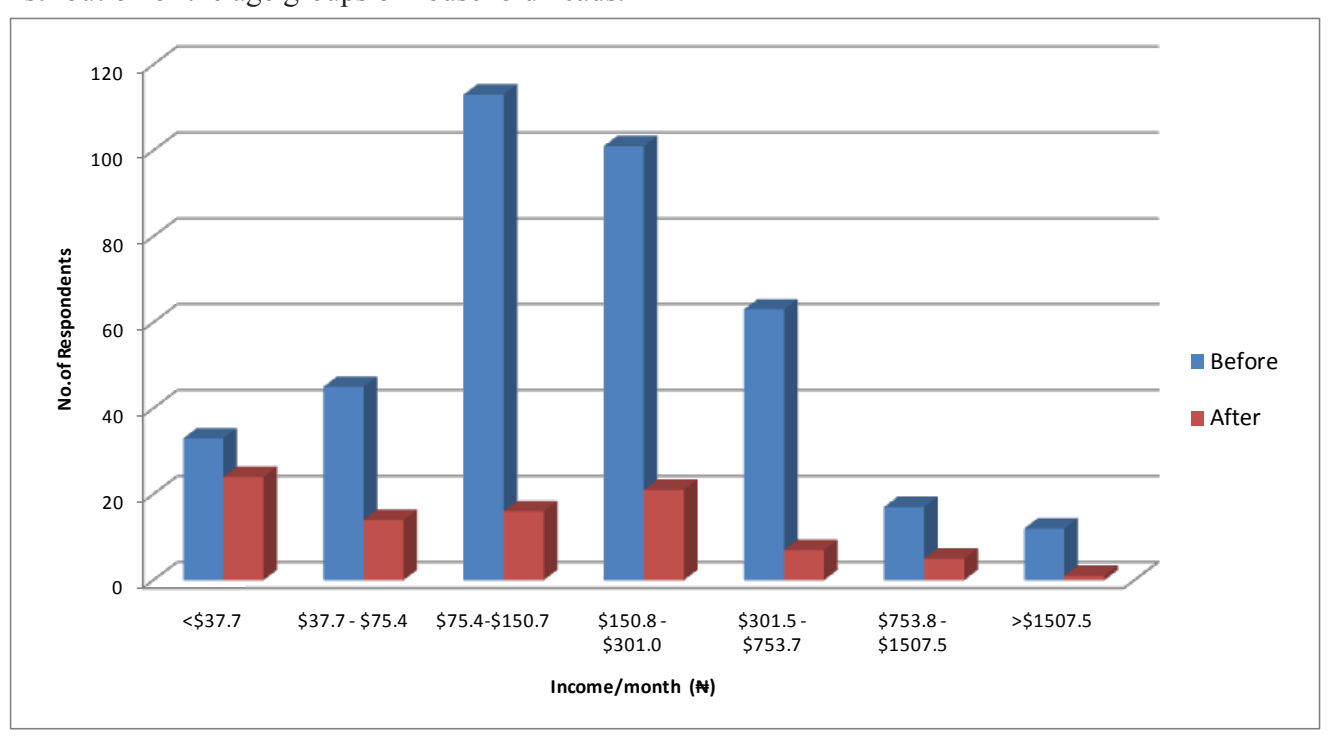

Figure 2: Distribution of the Income rate of respondents before and after the disaster.

$(69.2 \%)$ of the respondents have lost their jobs as a result of floods. On safety and security, while $90(20.8 \%)$ had safety and security concerns in their residence before the disaster, in the aftermath of the flood, $251(58.1 \%)$ felt insecure. Majority of the respondents $357,(82.6 \%)$ had children in school before the disaster while $189(43.8 \%)$ were not able to keep their children in school due to the disaster.

Access to insecticide treated bed nets (LLNT) reduced from 336 (78.9\%) before the disaster to 243 (57.7\%) after the flood. Comparison of the use of LLTN was significant among the three states (Table 2). For 178 respondents, Government was the source of the treated nets while 172 purchased theirs in the open market. $272(63 \%)$ of the respondents reported at least one episode of being sick since their sojourn in the temporary shelter and 147 (34\%) said malaria was the cause of their illness. Very few respondents also reported diarrhoea and pneumonia 7 (1.6) and $5(1.2 \%)$ respectively, as causes of illness. Less than half of those ill (38\%) received treatment from government clinic near the camp, $26(6 \%)$ bought medicine from a chemist and $35(8.1 \%)$ received no treatment.
River/stream and well were the major (72.2\%) sources of water used by households before the disaster while only $90(20.8 \%)$ had access to pipe borne water. However access to pipe borne water increased to $22 \%$ and river/well reduced to $32 \%$ after the flood disaster. However these differences were not statistically significant $(\mathrm{p}=0.99)$ (Figure 3$)$. Also, $63.3 \%$ of respondents eat less as a result of the disaster compared to $51.7 \%$ before the disaster. Though the number of IDPs using other means of health care services after the disaster increased when compared with type of health services before the disaster (Figure 4), comparison between healthcare facilitites used by respondents before and after disaster revealed no statistically significant difference $(\mathrm{p}=0.48)$.

Majority of IDPs complained of being sick since the disaster $(p=0.033)$ and this spread across states $(p=0.00)$. Good feeding habit and access to insecticide treated net was significant before disaster $(p=0,000)$ (Table 2). Also, over $90 \%$ were unable to have sex since disaster, although significant number of married answered affirmative to $\operatorname{sex}(p=0.000)$. Further, $14(82.4 \%)$ of the 17 pregnant women had access to antenatal care before the disaster 
Table 2: Comparative Analysis of Medical and Socio-economic Challenges among IDPs from the three states.

\begin{tabular}{|c|c|c|c|c|c|}
\hline Variable List (N) & States & Yes (\%) & No $(\%)$ & $\mathbf{X}^{2}$ & P - value \\
\hline \multirow{3}{*}{ Sickness since disaster $(\mathrm{N}=425)$} & Edo & $84(52.2)$ & $77(47.8)$ & \multirow{3}{*}{15.838} & \multirow{3}{*}{$<0.001$} \\
\hline & Kogi & $102(70.3)$ & $43(29.7)$ & & \\
\hline & Benue & $86(72.3)$ & $33(27.7)$ & & \\
\hline \multirow{3}{*}{ Use of LLTN $(\mathrm{N}=421)$} & Edo & $74(45.1)$ & $90(54.9)$ & \multirow{3}{*}{34.768} & \multirow{3}{*}{$<0.001$} \\
\hline & Kogi & $77(54.2)$ & $65(45.8)$ & & \\
\hline & Benue & $92(80.0)$ & $23(20.0)$ & & \\
\hline \multirow{3}{*}{ Risk of HIV (N=368) } & Edo & $2(1.5)$ & $129(98.5)$ & \multirow{3}{*}{44.09} & \multirow{3}{*}{$<0.001$} \\
\hline & Kogi & $16(12.3)$ & $114(87.7)$ & & \\
\hline & Benue & $3(2.5)$ & $104(97.2)$ & & \\
\hline \multirow{3}{*}{ Forced to have sex (91) } & Edo & $1(4.2)$ & $23(95.8)$ & \multirow{3}{*}{2.8} & \multirow{3}{*}{0.244} \\
\hline & Kogi & $0(0.0)$ & $64(100.0)$ & & \\
\hline & Benue & $0(0.0)$ & $3(100.0)$ & & \\
\hline \multirow{3}{*}{ Domestic Violence (N=92) } & Edo & $0(0.0)$ & $25(100.0)$ & \multirow[b]{3}{*}{1.357} & \multirow[b]{3}{*}{0.507} \\
\hline & Kogi & $3(4.7)$ & $61(95.3)$ & & \\
\hline & Benue & $0(0.0)$ & $3(100.0)$ & & \\
\hline
\end{tabular}

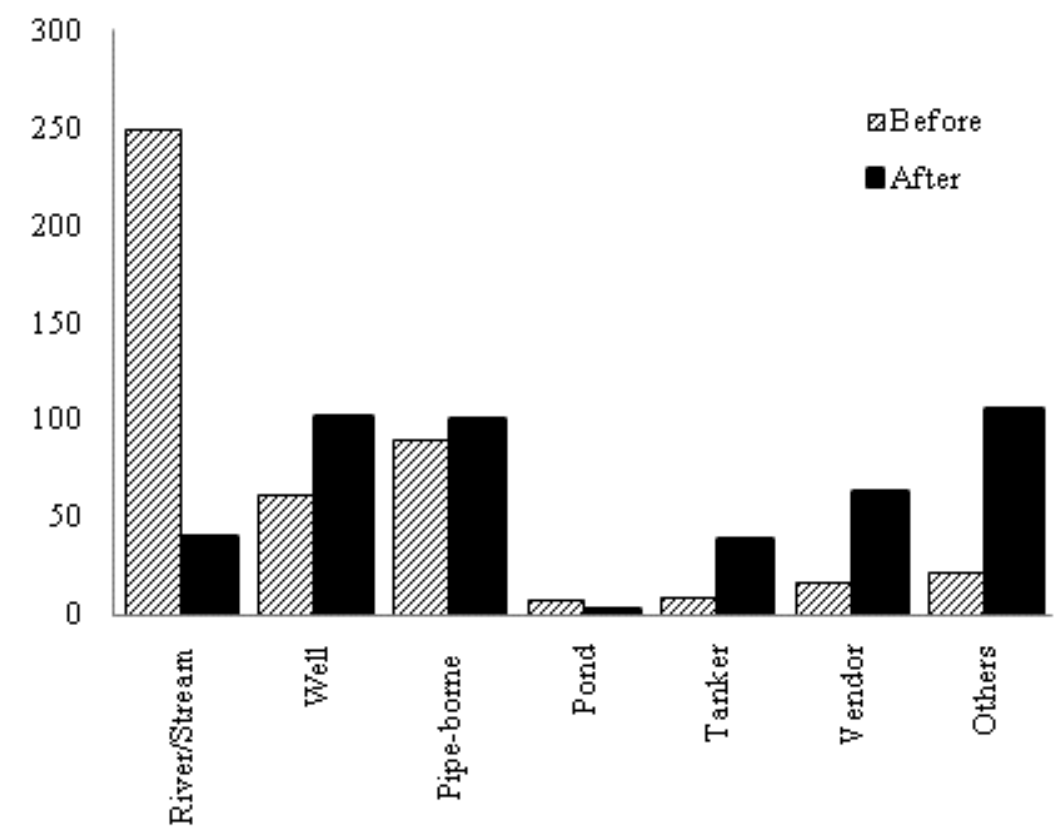

Figure 3: Distribution of source of water supply to IDPs before and after the disaster.

while $8(53.3 \%)$ had access after the disaster. More men compared to women thought they were at risk of HIV during disaster but insignificant number of IDPs thought otherwise $(\mathrm{p}=0.555)$. HIV risk (unprotected sex) was high among age groups 21-30 years. Insignificant number of IDP's affirms that there_was no mistreatments in camps across state, gender, age and marital status. About half of the responded recorded one form of injury or the other, 68 (16.2\%) lost family members to death and 103 (24.5\%) saw someone dying while $12(2.8 \%)$ people responded to being mistreated physically in the cause of the disaster while only $1(0.2 \%)$ female answered yes to being forced to have sex in camp. Further, more than half of responded had difficulties getting help from government.

\section{DISCUSSION}

The floods in 2012 imposed severe direct and indirect damages on social infrastructure and economic sectors, as well as health challenges of the rural areas of affected states in Nigeria. The demography of the study population revealed that the greater number of the household heads interviewed were young adults (within the age 21 and 


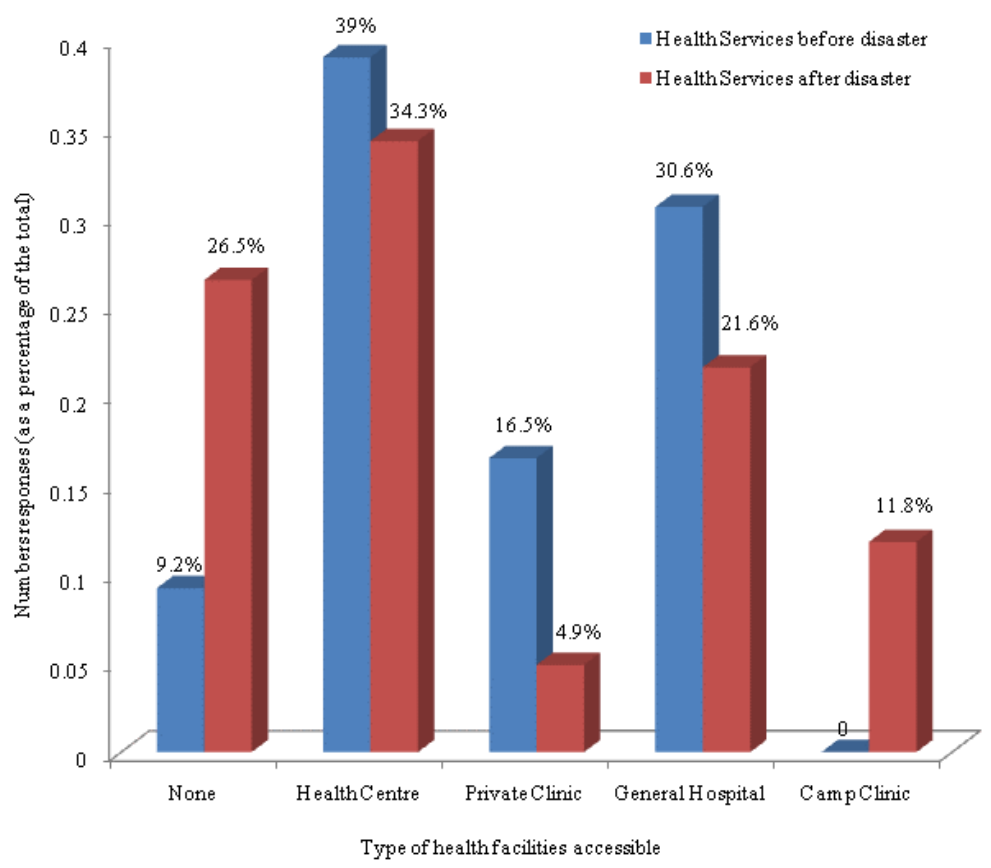

Figure 4: Distribution of the Health facilities Types available to respondents.

40). This is typical of the early marriages in rural settings (Singh and Smara, 1996). The study revealed farming as the main source of livelihood. Colossal loss of income is one of the major aftermaths of flooding because many of the flooded areas become inaccessible due to breakdown of key infrastructure, including bridges and roads, and industrial and agricultural activities come to a halt or are drastically reduced. This was revealed in our study (Fig. 2) with reduction in income ranging from $\$ 75.4-\$ 150.7$ to less than $\$ 35.2$ (per month). In 2010, Armah et al. (2010) reported $90 \%$ loss of jobs due to aftermath effects of flooding. Our study also showed that about 70\% lost their job due to the flood. Considering the fact that over $50 \%$ of respondents in our studies are also farmers.

Most cultures in Nigeria place a high value on family, thus close relatives and friends tend to live closer especially in rural areas. However, with these respondents, staying with relatives and friends was not an option as their communities were completely submerged by the flood. This probably accounted for the large proportion of respondents who sought shelter in schools and other make shift camps. This also adversely affected the education of the children in the areas not affected by floods as the schools in such areas were used as camps for displaced persons from flooded areas. This will drastically slow down the progress towards achieving the millennium goal (Achoka and Maiyo, 2008). It was also observed that some of this schools lacked adequate sanitary facilities like toilet, hence proper sanitary procedures could not be observed by the IDP's. Therefore, schools, especially in areas prone to seasonal disasters like flood should be equipped with better sanitary facilities so as to prevent outbreaks of diseases.

Furthermore, disaster had a negative impact on education of the children in both the affected and hosting communities. While the flooded communities lost the school structures to flood, schools in the host communities were turned to shelter. As reported by other authors, this seems to be the trend in most developing countries because of lack of preventive risk policy (The Associated Programme on Flood Management, 2006; Achoka and Maiyo, 2008; Amanchukwu et al., 2015). The sampled communities showed a lot of diversity on the type of drinking water sources they had. It was evident that rivers/stream is the most common water sources that communities used for drinking and other household chores. This was not surprising as they all lived along the river basins. However, analyses revealed that pipe borne water/ borehole and well were the major source of water used at host communities. Flood issues are influenced by several factors including the overall social economic and political setting of the area concerned (The Associated Programme on Flood Management, 2006). Therefore, the change in source of water source could be as a result of the effort from the Government at the local level in alleviating the pains of the IDP's. Though this report recorded low level of violence $(2.8 \%)$ in the IDP camps visited as compare to that reported $(14 \%)$ by center for human rights and global justice (Center for Human Rights and Global Justice, 2011). Forced intercourse was also reported by a female (Table 2). The low response could be because many respondents do not openly speak about such behaviour or experiences of sexual violence due to cultural and religious beliefs (Dery et al., 2014; Taylor and Putt, 2007).

The disaster also has its impact on health. Apart from sanitary issues which cut across sex and age, children and pregnant women who are vulnerable groups were most hit by the health challenges as a result of the flood. Damage to infrastructure led to reduction in access to health (Gray, 2008). Among the 14 pregnant women interviewed, only 8 $(57.1 \%)$ had access to antenatal care and the major reason being lack of money to access care and transportation to the nearest facility. The number of reported sickness was 
significant ( $p=0.03$ ) among respondents in this study. This could be as a result of the overcrowding and lack of access to malaria control (reduced access to mosquito treated nets) and the reduced access to health care facilities. In this study, good feeding habit was better before the disaster $(\mathrm{p}=0.000)$ however, the study did not consider the quality and class of food by participants and so this is the limitation in this study. Also, the risks of HIV were high among men when compared to women. This risk was prominent among age group $21-30$ years.

\section{CONCLUSIONS}

Results from this study depicts that IDP's are exposed to socio-economic issues. Health problems such as psychological issues and diseases such as malaria and diarrhoea due to improper sanitary procedures and overcrowding were suggestive from this study. It is important that those who provide medical care need to be aware of the increased medical needs of the people who have experienced floods. Suffering with psychological trauma may continue long after the water has receded, therefore, Government should focus on key building blocks for collective action which include developing a shared understanding and intervention policy for flood prone victims in Nigeria. Further, flood prevention and mitigation strategies need to be put in place in flood prone areas because these play important role in protecting people and socio-economic development from devastating effect of flooding. Governments should put in place policy that would alleviate suffering during difficult time as such as a result of disaster. A major limitation of this study is the inability to embark on post flood data collection after the IDP's was restored to their communities. Therefore further research could focus on post IDP settlement data collection.

\section{CONFLICT OF INTEREST}

Authors hereby declare that there is no conflict of interest.

\section{REFERENCES}

Achoka, J. S. K. and Maiyo, J. (2008). Horrifying disasters in western Kenya; Impact on education and national development. Educational Research and Review 3(3):154-161.

Amanchukwu, R. Amadi-Ali, A. T. and Ololube, N. P. (2015). Climate Change Education in Nigeria: The Role of Curriculum Review. Education 5(3):71-79.

Armah, F. A., Yawson, D. S., Yengoh, G. T., Odoi, J. O. and Afrifa, E. K. A. (2010). Impact of Floods on Livelihoods and Vulnerability of Natural Resource Dependent Communities in Northern Ghana. Water 2:120-139.

Awopetu, R. G., Awopetu, S. O. and Awopetu, M. S. (2013). The impact of flood on the socio-economic status of residents of Wadata and Gado-villa communities in the Makurdi metropolitan area of Benue State, Nigeria. Disaster Management and Human Health Risk III 133:347-357.

Babanyara, Y. Y., Usman, H. A. and Saleh, U. F. (2010). An Overview of Urban Poverty and Environmental Problems in Nigeria. Journal of Human Ecology
31(2):135-143.

Centre for Human Rights and Global Justice (2011). Sexual Violence in Haiti's IDP Camps: Results of a Household Survey. 1-9 pp.

Dery, I. (2014). Domestic Violence against Women in Ghana: An Exploratory Study in Upper West Region, Ghana. International Journal of Humanities and Social Science 4(12): 228 -244.

Du, W., Fitzgerald, G. J., Clark, M. and Hou, X. Y. (2010). Health impacts of floods. Prehospital and Disaster Medicine 3:265-72.

Gray, S. (2008). Long-term health effects of flooding. Journal of Public Health 30(4):353-354.

Internal Displacement Monitoring Centre (2012). Nigeria: Increasing violence continues to cause internal displacement. A profile of the internal displacement situation. Norwegian Refugee Council Chemin de Balexert 7-9 1219 Geneva, Switzerland, available at www.internal-displacement.org.

Lundgren, L. and. Jonsson, A. (2012). Assessment of Social Vulnerability: A Literature Review of Vulnerability Related to Climate Change and Natural Hazards. CSPR Briefing 9:1-16.

Mcmichael, A. J., Campbell-Lendrum, D. H., Corvalán, C. F., Ebi, K. L., Githeko, A. K., Scheraga, J. D. and Woodward, A. (2003). Climate change and human health: Risks and Responses. World Health Organization. Geneva.

Musa, Z. N. and Mynett, A. (2014). The Niger Delta's Vulnerability to floods due to sea level rise. Natural Hazards and Earth System Sciences 14:3317 - 3329.

Ologunorisa, T. E. and Abawua., M. J. (2005). Flood Risk Assessment: A Review. Journal of Applied Sciences and Environmental Management 9(1):57-63.

Oyinloye, M., Olamiju, I. and Adekemi, O. (2013). Environmental Impact of Flooding on Kosofe Local Government Area of Lagos State, Nigeria: A GIS Perspective. Journal of Environment and Earth Science 3(5):57-66.

Singh, S. and Samara, R. (1996). Early Marriage among women in developing countries. International Family Planning Perspective 22:144 -157.

Taylor, N. and Putt, J. (2007). Adult sexual violence in Indigenous and culturally and linguistically diverse communities in Australia. Trends and Issues in Crime and Criminal Justice 345:1-6.

The Associated Programme on Flood Management (2006). Social aspects and Stakeholder Involvement in Integrated flood Management: Associated Programme On Flood Management. World Meteorological Organization. APFM Technical Document No. 4, Flood Management Policy Series (C) World Meteorological Organization, ISBN: 92-63-11008-5N.

World Health Organization (2013). "Floods in the WHO European Region: health effects and their prevention" WHO Regional Office for Europe UN City, Marmorvej 51 DK-2100 Copenhagen, Denmark. 